\title{
Accuracy of clinical indicators of Nursing diagnoses hyperthermia and hypothermia in newborns
}

\author{
Acurácia dos indicadores clínicos dos diagnósticos de Enfermagem hipertermia e \\ hipotermia em recém-nascidos
}

\section{Precisión de los indicadores clínicos de los diagnósticos de Enfermería hipertermia e hipotermia en recién nacidos}

Fernanda Cavalcante Braga ${ }^{1}$, Alessandro Rodrigues Costa Santos ${ }^{2}$, Natália Barreto de Castroํㅜ ${ }^{1}$ Marília Mendes Nunes $^{1}$, Marcos Venícios de Oliveira Lopes ${ }^{1}$, Viviane Martins da Silva ${ }^{1}$

This study aimed at determining the accuracy of clinical indicators of Nursing diagnoses hyperthermia and hypothermia in newborns. This was a cross-sectional study carried out in 2013 in a reference maternity in Fortaleza, CE, Brazil with 46 newborns. Data collection was performed using an instrument developed based on the clinical indicators of these diagnoses, both from NANDA International. Diagnostician nurses were selected to perform diagnostic inference. Irritability, restlessness, bradycardia, pallor, jaundice, tachycardia, slow capillary refill and peripheral vasoconstriction were specific clinical indicators for hypothermia and body temperature below the normal range was the only sensitive indicator. Tachypnea, vasodilation and apnea were specific to hyperthermia however sensitive indicators were not found. We believed that the findings of this research can contribute to proper and fast inference of hypothermia and hyperthermia in newborns. Descriptors: Body Temperature Regulation; Newborn; Nursing Diagnosis.

Objetivou-se determinar a acurácia dos indicadores clínicos dos diagnósticos de Enfermagem hipertermia e hipotermia em recém-nascidos. Estudo transversal realizado em 2013, em maternidade de referência em Fortaleza, CE, Brasil, com 46 recém-nascidos. A coleta de dados foi feita por meio de instrumento construído baseado nos indicadores clínicos desses diagnósticos, ambos da NANDA Internacional. Foram selecionados enfermeiros diagnosticadores para realizarem inferência diagnóstica. Irritabilidade, inquietação, bradicardia, palidez, icterícia, taquicardia, preenchimento capilar lento e vasoconstrição periférica foram indicadores clínicos específicos para hipotermia, sendo que temperatura abaixo dos parâmetros normais foi o único indicador sensível encontrado. Taquipneia, vasodilatação e apneia foram específicas para hipertermia, mas não foram encontrados indicadores sensíveis. Acredita-se que os achados da presente pesquisa possam colaborar para a inferência correta e rápida de hipotermia e hipertermia em recém-nascidos.

Descritores: Regulação da Temperatura Corporal; Recém-nascido; Diagnóstico de Enfermagem.

El objetivo fue determinar la precisión de los indicadores clínicos de los diagnósticos de Enfermería hipertermia e hipotermia en recién nacidos. Estudio transversal, llevado a cabo en 2013, en maternidad de Fortaleza, CE, Brasil, con 46 recién nacidos. La recolección de datos se realizó a través de instrumento basado en indicadores clínicos de estos diagnósticos, provenientes de la NANDA Internacional. Fueron seleccionados enfermeros diagnosticadores para realizar inferencia diagnóstica. Irritabilidad, inquietud, bradicardia, palidez, ictericia, taquicardia, enlentecimiento del rellenado capilar y vasoconstricción periférica fueron indicadores clínicos específicos para hipotermia y reducción de la temperatura corporal por abajo del límite normal fue el único indicador sensible. Taquipnea, vasodilatación y apnea fueron específicas para hipertermia, pero indicadores sensibles no fueron encontrados. Los resultados de esta investigación pueden contribuir a la inferencia correcta y rápida de hipotermia e hipertermia en recién nacidos.

Descriptores: Regulación de la Temperatura Corporal; Recién nacido; Diagnóstico de Enfermería.

\footnotetext{
${ }^{1}$ Universidade Federal do Ceará. Fortaleza, CE, Brazil.

${ }^{2}$ Faculdade Maurício de Nassau. Fortaleza, CE, Brazil. 


\section{Introduction}

The thermoregulation is critical to the stability of the newborn. It is a term that refers to the body's ability to promote balance between the production and loss of heat, maintaining body temperature within the normal range. The temperature values are considered normal when they are between $36.5^{\circ}$ and $37.5^{\circ} \mathrm{C}$ in newborns at term and between $36,3^{\circ} \mathrm{C}$ and $36,9^{\circ} \mathrm{C}$ in newborn preterm newborns ${ }^{(1)}$.

The nurse has the role of monitoring the body temperature of the newborn, seeking to maintain a stable neutral thermal environment and promote a qualified nursing care. So it is necessary that the nurse has vast knowledge regarding the mechanisms of thermal control of heat loss and the thermal instability of this population ${ }^{(2)}$. Furthermore, the nurse must have the ability to accurately infer Nursing diagnoses related to thermoregulation, amongst these stand out hyperthermia and hypothermia.

Hyperthermia is defined as: "body temperature above the normal range." Hypothermia is the "body temperature below the normal range." Both diagnoses belong to the taxonomy II of International NANDA (NANDA-I), to the 11 domain: (Security/protection) and class 6 (thermoregulation) ${ }^{(3: 538-9)}$.

The concept of these diagnostic leads nurses to use the increase or reduction of body temperature as the only clinical indicators to determine the presence or absence of these diagnoses. But there are other important indicators that support the nurse to infer these diagnoses.

The accuracy of a Nursing diagnosis is defined as the judgment of an evaluator as to the degree of relevance, specificity and consistency of existing indicators for diagnosis ${ }^{(4)}$.

The accuracy measures are sensitivity, specificity, and predictive values (positive and negative). Sensitivity is the correct identification of the presence of a clinical indicator in patients with the diagnosis. Specificity is the correct identification of the absence of a clinical indicator in patients without diagnosis. The predictive value of a clinical indicator, if positive, is the presence of Nursing Diagnosis in patients with such clinical indicator. And if negative, this measurement refers to the absence of nursing diagnosis in patients without such clinical indicator ${ }^{(5)}$.

Given this context, the aim of this study is to determine the accuracy measures of clinical indicators from nursing diagnoses hyperthermia and hypothermia in newborns.

\section{Method}

It is a descriptive study with cross-sectional design. It has been developed in the neonatal unit of a medium-risk in a reference maternity hospital in Fortaleza, capital of Ceará, in Northeast Brazil. To participate in the study, newborns should meet the following inclusion criteria: have up to 28 days of life, have been admitted in the period July-October 2013; being clinically and hemodynamically stable and being in a heated cradle. During this period, 46 newborns met these criteria and were selected to participate. We chose not to include in the sample, the newborns that were in an incubator or phototherapy, as it was not allowed to manipulate them in this condition in the unit where the study was performed, whereas they were considered clinically unstable.

The data collection took place through the application of a instrument constructed based on the two defining characteristics of nursing diagnoses that were investigated in this study, by performing sociodemographic data gathering, investigation of subjective data, physical examination on each newborn and consultation with respective records for verification of laboratory test results.

It is noteworthy that some clinical indicators are important to determine both diagnoses and are not delineated in the NANDA-I, been included in this study $^{(1)}$. 
For the diagnosis of hypothermia were included: apnea, bradycardia, abdominal distension, respiratory distress, hypotonia, hypoxia, jaundice, restlessness, irritability, lethargy, skin blemishes, increased peripheral resistance, response to decreased stimulation, decreased $\mathrm{O}_{2}$ saturation and peripheral vasoconstriction. For the diagnosis of hyperthermia, were included: apnea, coma, irritability, lethargy, stupor and vasodilatation ${ }^{(1)}$.

The clinical indicator "trembling" can be referred to as a physiological reflex of newborns, so that it was not evaluated, despite being present in the NANDA-I ${ }^{(1,6)}$. Due to blood pressure measurement being a uncomfotable procedure to the newborn, it was preferred to not assess clinical hypertension indicator, since it could influence the emergence of other indicators that would not meet up with the actual state of the newborn, as, for example, the clinical indicators irritability and restlessness.

Two diagnostician nurses were selected to perform diagnostic inference. They had participated as diagnosticians nurses in studies of diagnostic accuracy, had published articles on nursing diagnoses and clinical practice of at least six months. For this, we used the criteria for selection experts in validating diagnostic content ${ }^{(7)}$.

46 worksheets were organized, one for each newborn, in the Microsoft Excel® 2007 software. In them, was described the presence or absence of clinical indicators, as well as additional clinical data when relevant. It was used a standard operational procedure of the clinical indicators from Nursing diagnoses hypothermia and hyperthermia. These spreadsheets were sent to diagnosticians nurses through electronic mail to the diagnostic inference.

The congruence of diagnostic inferences among diagnosticians nurses was verified. When there was disagreement, a discussion occurred between the partners so there would be consensus. We used the Statistical Package for the Social Sciences and the $\mathrm{R}$ statistical package, for calculating the measures of accuracy, descriptive statistics and measures of central tendency. The admitted cutoff point was $80 \%$ for the calculation of measures of accuracy. After statistical analysis, the data were organized into tables.

The ethical aspects were observed in all aspects of the study, in accordance with Resolution $466 / 12$. The project was referred to Plataforma Brasil and received assent of the Research Ethics Committee of the institution where data were collected under the protocol 325.704. All parents and diagnosticians nurses signed the Statement of Informed Consent form.

\section{Results}

According to socialdemographic data, the median age of the newborns was 4.50 days (interquartile range of 8 ) and $60.9 \%$ were male. The average birth weight was $2608,8 \mathrm{~g}$ (standard deviation of 839.18); $52.2 \%$ were newborns at term; $67.4 \%$ were born in Fortaleza. The most prevalent medical diagnoses were Respiratory Distress Syndrome (26.1\%), early jaundice (13\%) and prematurity $(6.5 \%)$.

The Nursing Diagnoses hypothermia was present in $54.3 \%$ of the sample. The most prevalent clinical indicators were: respiratory distress (69.6\%), hypoxia (67.4\%), cyanosis in the nail beds (65.2\%) temperature below the normal range $(47.8 \%)$ and lethargy $(45,7 \%)$.

The accuracy measures from clinical indicators of the Nursing Diagnosis hypothermia were calculated and are shown in table 1 below. 
Table 1 - Sensitivity (Se), specificity (S), positive predictive value $(\mathrm{PV}+)$ and negative predictive value (PV-) for each clinical indicator of Nursing Diagnoses hypothermia

\begin{tabular}{|c|c|c|c|c|}
\hline Clinical indicators & $\operatorname{Se}(\%)$ & $S(\%)$ & $P V+(\%)$ & PV - $(\%)$ \\
\hline $\begin{array}{l}\text { Temperature below the } \\
\text { normal range }\end{array}$ & 88.00 & 100.00 & 100.00 & 87.50 \\
\hline Cyanosis in the nail beds & 76.00 & 47.61 & 63.33 & 62.50 \\
\hline Hypoxia & 76.00 & 42.85 & 61.29 & 60.00 \\
\hline Respiratory distress & 72.00 & 33.33 & 56.25 & 50.00 \\
\hline Lethargy & 52.00 & 61.90 & 61.90 & 52.00 \\
\hline Cold skin & 40.00 & 100.0 & 100.00 & 58.33 \\
\hline Irritability & 36.00 & 85.71 & 75.00 & 52.94 \\
\hline Restlessness & 32.00 & 90.47 & 80.00 & 52.77 \\
\hline Bradycardia & 24.00 & 90.47 & 75.00 & 50.00 \\
\hline Skin blemishes & 24.00 & 71.42 & 50.00 & 44.11 \\
\hline Paleness & 20.00 & 95.23 & 83.33 & 50.00 \\
\hline Piloerection & 16.00 & 76.19 & 44.44 & 43.24 \\
\hline Jaundice & 12.00 & 80.95 & 42.85 & 43.58 \\
\hline Tachycardia & 12.00 & 90.47 & 60.00 & 46.34 \\
\hline Hypotonia & 8.00 & 90.47 & 50.00 & 45.23 \\
\hline Slow capillary refil & 4.00 & 85.71 & 25.00 & 42.85 \\
\hline Perpheral vasoconstriction & 4.00 & 95.23 & 50.00 & 45.45 \\
\hline
\end{tabular}

Nine indicators were considered specific for the diagnosic hypothermia, namely: paleness and peripheral vasoconstriction (95.23\%), restlessness, bradycardia, tachycardia and hypotonia (90.47\%), irritability and slow capillary refill (85.71\%) and jaundice (80.95\%). This means that, in patients without a hypothermia diagnosis, these indicators were absent.

Restlessness and paleness showed good levels of positive predictive value (80\% and $83.33 \%$ ) respectively. This means that in the presence of these indicators, the hypothermia diagnosis was present. Temperature below the normal range appeared as a substantial clinical indicator (88\%) and high negative predictive value (87.5\%). This means that, in patients with the diagnosis, this indicator was present and that in the absence of this indicator, the diagnosis was absent.

Despite the cold skin and temperature below the normal parameters have reached high levels of specificity (100\%) and positive predictive value (100\%), they reached the value 1.00 in the confidence interval and are not considered valid measures. Accordingly, no clinical indicator was considered simultaneously sensitive and specific for inference of hypothermia.

The Nursing Diagnosis hyperthermia was present in $8.7 \%$ of the sample. The most prevalent clinical indicators were: warm skin to the touch (58.7\%), lethargy (45.7\%), irritability $(26.1 \%)$ and reddened skin $(21.7 \%)$.

The accuracy measures from clinical indicators of Nursing Diagnosis hyperthermia were calculated and are found below in Table 2 .

Table 2 - Sensitivity (Se), specificity (S), positive predictive value $(\mathrm{PV}+)$ and negative predictive value (PV-) for each clinical indicator of Nursing Diagnoses hyperthermia

\begin{tabular}{lcccc}
\hline Clinical indicators & $\mathbf{S e}(\%)$ & $\mathbf{S}(\%)$ & $\mathbf{P V + ( \% )}$ & $\mathbf{P V}-(\%)$ \\
\hline $\begin{array}{l}\text { Increase in body tempera- } \\
\text { ture above the normal pa- } \\
\text { rameters }\end{array}$ & 100.00 & 100.00 & 100.00 & 100.00 \\
Warm skin & 100.00 & 45.23 & 14.81 & 100.00 \\
Lethargy & 25.00 & 52.38 & 4.76 & 88.00 \\
Tachypnea & 25.00 & 90.47 & 0.00 & 90.47 \\
Vasodilation & 0.00 & 95.23 & 0.00 & 90.90 \\
Apnea & 0.00 & 90.47 & 0.00 & 90.47 \\
Reddened skin & 0.00 & 76.19 & 0.00 & 88.88 \\
Irritability & 0.00 & 73.80 & 0.00 & 88.57 \\
\hline
\end{tabular}

Clinical indicators tachypnea, vasodilatation and apnea, were specific $(90.47 \%, 95.23 \%$ and $90.47 \%$ ) respectively, to the inference of hyperthermia, which means that in the absence of diagnosis, these indicators were absent.

Lethargy, tachypnea, vasodilatation, apnea, reddened skin and irritability showed good negative predictive values $(88 \%, 90.47 \%, 90.90 \%, 90.47 \%$, $88.88 \%$ and $88.57 \%$ ) respectively. This implies that when the diagnosis was absent, these indicators were also absent.

Despite the increase of body temperature 
above the normal parameters have presented high sensitivity, specificity, positive and negative predictive value; and the skin warm to the touch has presented high sensitivity and negative predictive value, they reached 1.00 value at confidence interval, being invalid. Indeed, no indicator was sensitive to hyperthermia inference.

\section{Discussion}

The thermoregulation is a physiological function related to the success of the circulatory and respiratory adaptation of the newborn immediately after birth ${ }^{(8)}$. Due to the complexity and importance of thermoregulation to the stability of the newborn, it is necessary that the nurse has extensive knowledge of the thermal control mechanism and the thermal instability of these patients, since the care related to the control and maintenance of body temperature are essential for their survival ${ }^{(9)}$.

Some factors predispose newborns to heat loss, as the large surface area to weight ratio, inefficient thermal insulation due to the thin layer of fat and the mechanism of heat generation, i.e. thermogenesis without "trembling" ${ }^{(10)}$. The newborn responds to cooling stress with vasoconstriction and a decrease in skin temperature, which can be the first signs of development of hypothermia. This may occur due to radiation, conduction, convection or evaporation ${ }^{(1)}$.

Newborns have difficulty dissipating heat in superheated environments and are susceptible to developing infections, especially when premature, increasing the risk of hyperthermia ${ }^{(11)}$. Defective equipment, incorrect use of heating lamps, use of prostaglandins, septicemia, incubator next to the sun, among other factors constitute risk of emerging hyperthermia that occurs through peripheral vasodilation due to the efforts of the body to eliminate heat ${ }^{(1)}$.

Considering this, it is noticed that the thermal instability of the newborn may contribute to the manifestation of some Nursing Diagnosis, including hypothermia and hyperthermia. To a correct diagnostic inference, it is necessary that nurses use clinical reasoning and know which are the most sensitive and specific indicators for both clinical diagnostics.

Adequate diagnostic inference, through the investigation of sensitive and specific clinical indicators to identify these diagnoses, allows rapid and effective interventions to achieve the expected results. The process of diagnostic reasoning assists the nurse in decision making about Nursing Diagnosis in a population. However, to have a quality service, the accurate diagnostic inference is essential ${ }^{(3)}$.

According to the consensus among diagnosticians nurses, $54.3 \%$ of the newborns evaluated presented the Nursing Diagnosis hypothermia and 8.7\% presented a Nursing Diagnosis hyperthermia. The findings of this research coincide with a study of hospitalized newborns in the intensive care unit of the Institute of Legal Medicine Prof. Fernando Figueira, in which $65.9 \%$ of the newborns showed hypothermia and $5.4 \%$ showed hyperthermia ${ }^{(11)}$.

In research with preterm newborns from the neonatal intensive care unit at New York University Medical Center with the goal of determining the etiology and incidence of hospital admissions, it was observed that preterm newborns have higher risk of developing hypothermia as admission diagnosis than newborns at term ${ }^{(12)}$. To check the influence of hospital transport of newborns on their mortality, a study involving preterm newborns transferred to the neonatal intensive care unit of the General Hospital of Caxias do Sul found that $27 \%$ showed hyperthermia during the trip ${ }^{(13)}$.

Clinical indicators of the Nursing Diagnosis hypothermia with the highest prevalence were: respiratory distress (69.6\%) and hypoxia (67.4\%). It is known that one consequence of hypothermia is increased of respiratory distress ${ }^{(1)}$.

Two other clinical indicators with high prevalence were: cyanosis in the nail beds (65.2\%) and temperature below the normal paramentres $(47.8 \%)$. Consistent with this finding, in a study of 
30 neonates with congenital malformation, 23\% showed the Nursing Diagnosis hypothermia which is characterized by temperatures below normal parameters and cyanosis in the nail beds ${ }^{(14)}$.

The clinical indicators of hyperthermia diagnosis most prevalent were: skin warm to the touch (58.7\%), irritability (26.1\%) and reddened skin $(21.7 \%)$. These data were similar to research on signs of hyperthermia, which mentions warm extremities, irritability and redness as present clinical indicators ${ }^{(1)}$.

Clinical indicators with improved specificity for hypothermia were: paleness (95.23\%), peripheral vasoconstriction (95.23\%), bradycardia (90.47\%), hypotonia $(90.47 \%)$, restlessness $(90.47 \%)$, tachycardia (90.47\%), irritability $(85.71 \%)$, slow capillary refill (85.71\%) and jaundice $(80.95 \%)$. Authors state that hypotonia, tachycardia, bradycardia, peripheral vasoconstriction, among other clinical manifestations, are the diagnosis of hypothermia, corroborating this study ${ }^{(15)}$.

In controversy with these results, in research aimed at evaluating peripheral vasoconstriction in newborns of extremely low birth weight during the reduction of body temperature in the first 12 hours of life, it is identified that the majority showed no peripheral vasoconstriction. The study authors stated that peripheral vasoconstriction is modified by several factors and not just for thermoregulation ${ }^{(16)}$.

Clinical indicators: tachypnea, apnea and

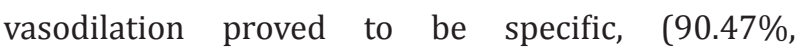
$95.23 \%$ and $90.47 \%$ respectively), for inference of hyperthermia and lethargy, tachypnea, vasodilation, apnea, reddened skin and irritability showed good negative predictive values $(88.0 \%, 90.47 \%$, $90.90 \%, 90.47 \%, 88.88 \%$ and $88.57 \%$ respectively). In convergence with this research, studies on the clinical symptoms of hyperthermia, refer as important clinical indicators: tachycardia, flushing, irritability, tachypnea, lethargy, and apnea. They also claim that in the attempt of the body to lower body temperature, vasodilation occurs ${ }^{(1)}$.

\section{Conclusion}

The shortage of literature on the Nursing Diagnosis Hypothermia and Hyperthermia in newborns made this search relevant on the other hand, made it difficult to discuss the results through comparisons.

For inference of hypothermia diagnosis, the following clinical indicators demonstrated to be specific: irritability, restlessness, bradycardia, paleness, jaundice, tachycardia, slow capillary refill, peripheral vasoconstriction and hypotonia. Temperature below the normal parametres was the only sensitive indicator found. For inference of hyperthermia diagnosis, the following clinical indicators demonstrated to be specific: tachypnea, apnea and and vasodilation. No sensitive indicator was found. Therefore, it is noticed that several clinical indicators that were included in this study were significant in measures of accuracy.

It is noteworthy that studies of diagnostic accuracy should be instigated, as they contribute to proper diagnostic inference, as well as the development of specific interventions for the clinical indicators of each Nursing Diagnoses. It is expected that similar studies are performed in view of the peculiarity of this population, as well as the need for special attention with the care for thermoregulation of the newborn.

It is believed that the findings of this research have contributed to the correct and fast inference of Nursing Diagnoses hyperthermia and hypothermia in newborns.

\section{Collaborations}

Braga FC contributed to the conception of the study, data collection, analysis, interpretation of data, writing and final paper. Santos ARC contributed to data collection and conception of the work. Castro NB and Nunes MM contributed to data interpretation, analysis and conception of the work. Lopes MVO contributed to statistics analysis, data interpretation and conception of work. Silva VM contributed with guidance, conception of work, data interpretation and writing of the article. 


\section{References}

1. McCall EM, Alderdice F, Halliday HL, Jenkins JG, Vohra S. Interventions to prevent hypothermia at birth in preterm and/or low birthweight infants. Cochrane Database Syst Rev. 2010; 23(1):CD004210.

2. Balbino AC, Cardoso MVLML, Lélis ALPA, Fontoura FC, Melo GM. Thermoregulation of the newborn: care during the admission in a pediatric emergency UNIT. Rev Rene. 2013; 14(2):320-30.

3. Herdman TH. Domínio 11: segurança/proteção, classe 6: termorregulação. In: Garcez RM, Barros ALBL, Cruz DALM, Avena $M$, Napoleão AA, Brasil VV, organizadores. NANDA International. Diagnósticos de Enfermagem da NANDA: definições e classificação 2012-2014. Porto Alegre: Artmed; 2013. p. 538-9.

4. Matos FGDOA, Cruz DDALMD. Development of an instrument to evaluate diagnosis accuracy. Rev Esc Enferm USP. 2009; 43(n. esp):1088-97.

5. Lopes MVO, Silva VM, Araújo TL. Methods for establishing the accuracy of clinical indicators in predicting nursing diagnoses. Int J Nurs Knowl. 2012; 23(3):134-9.

6. Fluhr JW, Darlenski R, Taieb A, Hachem JP, Baudouin C, Msika P, et al. Functional skin adaptation in infancy - almost complete but not fully competent. Exp Dermatol. 2010; 19(6):48392.

7. Seganfredo DH, Almeida MA. Nursing outcomes content validation according to Nursing Outcomes Classification (NOC) for clinical, surgical and critical patients.. Rev Latino-Am Enfermagem. 2011; 19(1):34-41.

8. Pugliesi VEM, Deutsch AD, Freitas M, Dornaus MFPS, Rebello CM. Efeitos do banho logo após o nascimento sobre as adaptações térmica e cardiorrespiratória do recém-nascido a termo. Rev Paul Pediatr. 2009; 27(4):410-5.
9. Knobel RB. Thermal stability of the premature infant in Neonatal Intensive Care. Newborn Infant Nurs Rev. 2014; 14(2):72-6.

10. Altimier L. Thermorregulation: what's new? What's not? Newborn Infant Nurs Rev. 2012; 12(1):5163.

11. Ventura CMU, Alves JGB, Meneses JA. Eventos adversos em unidade de terapia Intensiva neonatal. Rev Bras Enferm. 2012; 65(1):49-55.

12. Mally PV, Hendricks-Muñoz KD, Bailey S. Incidence and etiology of late preterm admissions to the neonatal intensive care unit and its associated respiratory morbidities when compared to term infants. Am J Perinatol. 2013; 30(5):425-31.

13. Araújo BF, Zatti H, Oliveira Filho PF, Coelho MB, Olmi FB, Guaresi TB, et al. Influência do local de nascimento e do transporte sobre a morbimortalidade de recém-nascidos prematuros. J Pediatr. 2011; 87(3):257-62.

14. Fontoura FC, Fontenele FC, Balbino AC, Cardoso MVLML. Newborn with congenital anomaly: a focus on nursing diagnosis. Rev Enferm UFPE Online [periódico na Internet]. 2012 [cited 2014 Jun 20]; 6(10):2387-95. Available from: http:// www.revista.ufpe.br/revistaenfermagem/index. php/revista/article/view/3225/pdf_1527

15. Bissinger RL, Annibale DJ. Thermoregulation in very low-birth-weight infants during the golden hour: results and implications. Adv Neonatal Care. 2010; 10(5):230-8.

16. Knobel RB, Holditch-Davis D, Schwartz TA, Wimmer JE. Extremely low birth weight preterm infants lack vasomotor response in relationship to cold body temperatures at birth. J Periontol. 2009; 29(12):814-21. 